\title{
Modeling the Student Experience in an Experiential Design Course: Faculty Projects
}

\author{
Jennifer Kushner, Jay K. Martin \\ University of Wisconsin-Madison
}

\begin{abstract}
We teach design courses that are experiential, in that student teams learn about design by engaging in actual design and project engineering with clients from the community. On two different occasions we participated directly in the student experience, with the students, by carrying out a project ourselves. This meant that we carried out all of the same activities as students such as site visits, brainstorming, situation analyses, design reviews, etc. Our purpose for doing this was twofold: To model our teaching, and to create a different dynamic between teachers and learners.
\end{abstract}

\section{Introduction}

We are intrigued with a simple question "how do people learn to be engineers?" On the surface the answer to this question is also simple. We might say that people learn to be engineers through study of engineering principles, of scientific laws, and with practice in labs or co-ops. In truth, learning to be an engineer, as with any profession, is much more complex, and requires more than mastery of predetermined content. Learning a profession involves a dynamic relationship between exposure to ideas, people, situations, and practice of the profession itself.

On two different occasions, we have chosen to model the design process by participating in a faculty project alongside students and their projects. We did this for two primary reasons. First, it was our intention to make explicit what we wanted students to learn by giving them an example to serve as a frame of reference. We wanted to set standards for student work by showing them what "good work" looks like. This required that we demonstrate our confidence in the design process by showing we could design something that would represent us well and also meet client needs. In short we wanted to make visible the struggle of learning.

Second, we wanted to create a different dynamic between teachers and learners. Our experience in working towards learner-centered education has demonstrated to us how difficult it is to create shared power in classrooms. Our aim in shifting the dynamic between teachers and learners is rooted in a belief that in order for students to become more selfdirected, they must be able to exercise some level of power in the process of learning. By presenting ourselves as "co-learners", we suggest shared power in the classroom. In addition, research suggests that traditional models of teaching, in which the teacher remains at a distance from both the subject and the students, are not effective for many people. For many learners, memorizing information does not provide sufficient understanding, and it is only through practical application that information can truly be synthesized and understood. Likewise, some students learn best when they are in close relationship to the material being 
taught. Because the learning in our course is situated in a "real life" context there are many unpredictable events that present themselves and are opportunities for learning. We want students to learn how to respond when they are presented with the unexpected. By providing different methods of exposure to the material, a teacher can bring a learner into closer relationship with the ideas, concepts and practices being taught. This concept is illustrated in Fig. 1, where both the New (Student) and Experienced (Faculty) Learners are addressing the unknown. The Experienced Learners have experience with and can demonstrate how to deal directly with the unknown. The New Learners, in addition to dealing with the unknown, are observers of the process being followed by the Experienced Learners. Of particular interest to us is the new pathway for interaction this activity introduces, as we think it might yield a new dynamic in the class.

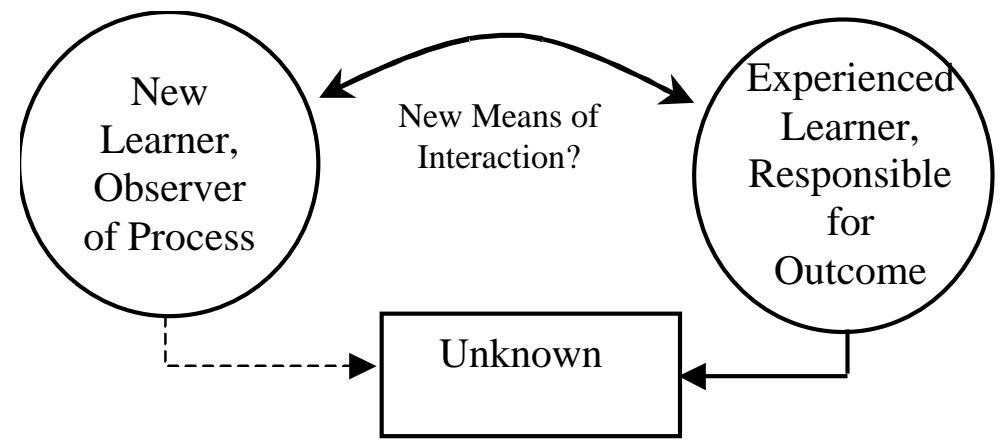

Fig. 1 Schematic representation of the faculty design project illustrating the possible interactions that occur from the experience.

Experiential design courses like the ones described here lend themselves well to teaching through modeling because some of the primary outcomes we strive for include student understanding of the design process, the ability to deal with ambiguity, and the ability to respond creatively to constraints and unexpected events. As co-learners, we can model the way we wrestle with and deal with each of these, with the students as observers of the process.

\section{First Experience with A Faculty Project}

Our first experience with a faculty project occurred in our introduction to engineering course. On the first day of class, the faculty asked each of the 220 students to write an essay describing why they should be the recipient of a faculty-designed and faculty-built "Ultimate Entertainment Center" (UEC), which we would design and build through the semester. The design and fabrication of the UEC was done on a timetable that was approximately one week ahead of where the students were in their design and building experience. The essays the students produced were interesting and creative, to say the least. One of the students was chosen from her effort on the essay, and we were off.

In short, it was an interesting experience. The faculty did all of the work the students were doing, which provided a continuous model for the students. For example, in previous semesters, we felt that students did not prepare effectively for their project site visits. In spite of our efforts, students could not conceptualize what would happen on the site visit, and did not really have an idea on how to prepare or what to prepare for. In this particular semester we attempted to remedy this by making a video that followed two students teams (actually made up of faculty teaching the class in role play mode) as they prepared for the site visit, 
carried out the site visit, and summarized the results of the visit. One of the teams (named Team A) was shaped from what we had observed from watching student teams in previous years. The other team (Team B) was developed from our ideas of how a team should prepare, carry out and learn from a site visit. Students in the class viewed this video and were asked questions like: "How will your team prepare differently than Team A? What did you observe Team B do that seemed to be particularly effective?" We have continued to use this video in every class since because of what we observed in the original class with improvements in how students conducted site visits.

For the semester as a whole, students indicated that the model they were seeing from the faculty was particularly helpful in providing a framework for their own activities. This feedback was continuous, throughout the semester, and also in the final student assessments collected at the end of the course.

The faculty project was also serious work. Faculty learned things they didn't know about design, building, and teamwork. One of the faculty, when working on a lathe at 3:00 AM one morning as the deadline drew near, thought of a saying of his father's as a form of recompense: "There is no experience that is so bad that you cannot learn something from." Finally, the project that was completed by the faculty impressed both the students and the faculty.

One thing occurred that surprised us following this first experiment with faculty projects. In the preparation meetings for the class following the semester in which the faculty project was undertaken, faculty teaching the course nearly revolted when it was announced (and assumed) that we would be engaged in another faculty project. This occurred in spite of a general agreement that student learning had benefited from our efforts on this project. The resistance to engage in this process again highlighted issues raised from the experience.

Table 1: Consideration of Issues Important When Evaluating Whether or Not to Engage in Faculty Design Projects.

\begin{tabular}{|c|c|}
\hline $\begin{array}{c}\text { Issues of Concern for Faculty Considering } \\
\text { Participating in Faculty Projects }\end{array}$ & Specifics of Concern \\
\hline Workload & This is going to be a lot of extra work. \\
\hline What is not done, what is left out? & We will not cover as much material. \\
\hline Uncertainty, Loss of control of agenda & Open-ended design is uncertain. \\
\hline Observation of Struggle & $\begin{array}{l}\text { Inevitably, there will be problems and } \\
\text { students will be front and center in } \\
\text { observing how faculty struggle with } \\
\text { problems. }\end{array}$ \\
\hline Team Behavior & $\begin{array}{l}\text { Without "functioning" team behavior, } \\
\text { project will not get completed. }\end{array}$ \\
\hline Loss of Model of Professor & $\begin{array}{l}\text { Traditional model may get lost. Students } \\
\text { may lose traditional model of faculty. }\end{array}$ \\
\hline Just In Time & $\begin{array}{l}\text { Will need to respond to "just-in-time" } \\
\text { unknowns. }\end{array}$ \\
\hline Balancing Tasks & $\begin{array}{l}\text { Tasks need to balanced in a way that may } \\
\text { be new for faculty. }\end{array}$ \\
\hline
\end{tabular}

Proceedings of the 2002 American Society for Engineering Education Annual Conference \& Exposition Copyright@ 2002, American Society for Engineering Education 
Since then, we have been attempting to identify issues that were of concern to the faculty because for others (and ourselves) interested in engaging in faculty design projects, it would be helpful to have some place to start in seeking to understand what facilitates and constrains this approach to teaching. The list of issues we have identified are based on our observation and participation, and are shown in Table 1, followed by discussion of each of these issues.

\section{Workload}

Faculty were very concerned that participating in a faculty design project would mean a substantial increase in the workload for the course. Some of their concern was legitimate, however, it is also possible that what was assumed to be additional time spent on the course was, in fact, time spent differently on the course. For example, working on the project one week ahead of the students necessitated that we adhere to a schedule that was not alterable. Sometimes, in order to meet deadlines, we spent more time in a given week that we might otherwise spend that week. Overall, however, in spite of concerns, there did not seem to be an overwhelming amount of additional effort required. In addition, any extra time was, in our opinion, not wasted. Faculty learned new skills in design, fabrication, presentation, collaborative writing and presenting.

If we do this, then what is left out?

Another concern faculty had was that important content would not get covered because there would not be sufficient time to cover everything plus engage in a project. Actually, a comparison of syllabi from the faculty project semester and the semester following and preceding indicate very little change in what we proposed to cover in the course. In reality, because we had an example that the students were interested that we could refer to throughout the course, the amount of material that was actually "learned" by the students was likely enhanced, although we did not test to see if this was the case.

\section{Uncertainty, Loss of Control}

A dominant issue that we had hardly considered initially was the uncertainty this activity generated for the faculty, and the concern about the possibility of loss of control of what happened to, with, and in the class. Because this is a design project, the outcome is uncertain. The process that the faculty follows will inevitably be messy, with times when we might be uncertain as to what we will produce. In addition, there was significant concern that we might not be able to produce a final product that reflected well on our efforts. It was apparent that for some of the faculty involved in the first project, this was an overwhelming concern which resulted in their lack of interest in doing this again.

\section{Observation of Struggle}

Consistent with issues of loss of control and uncertainty is the reality that there will be times when the faculty will struggle. And it is not difficult to imagine that this is a time when you have the students' undivided attention. The interaction that results may be one of the most powerful of the outcomes, yet having students observe your struggle is not a place of comfort for some faculty.

\section{Team Behavior}

It is sometimes ironic that faculty expect that students will participate in team activities that result in functional teams, but oftentimes have problems as team members themselves. A faculty design project will require a functioning team otherwise the project will not get completed. We learned this the hard way, as we started out with a very loose team 
organization, and our process and production suffered until we changed that and really focused on what we needed to be an effective team. For most of us, this was a new experience.

\section{Loss of Model of Professor}

Engaging in this activity may result in changes in the way students view and interact with faculty. While this is one of the reasons why we chose to participate, the new view students have with faculty may not be consistent with what every professor wants or needs. It can be difficult for some faculty to challenge their own understandings or assumptions about what a model professor should be. By positioning oneself as a co-learner, one becomes vulnerable to exposure related to "not knowing" or making "mistakes".

\section{Just-In-Time}

Because this is a design activity, much of the process will be just-in-time, in response to whatever is happening in the process. This means that it will not be possible to completely plan for what you will do during the semester ahead of time, and that you will not know ahead of time how or what you will need to prepare.

\section{Balancing Tasks}

Finally, because of all of the activities involved in carrying out a faculty-based design project, there is a need to be capable of balancing tasks that have to be completed. Some weeks you will have to work on the preliminary design, or a presentation, or fabrication, and at the same time you may need to prepare for a lecture specific to the class that will build your skills in balancing tasks.

\section{The Second Faculty Design Project}

The course in which the second faculty design project occurred is part of the University of Wisconsin-Madison's Engineering Projects in Community Service (EPICS) program. Interested readers should see the Purdue University EPICS website for further information about EPICS. For information on the EPICS program at the University of WisconsinMadison, please consult the website: epics.engr.wisc.edu. Fundamental to the EPICS program is the development of working partnerships between organizations in the community and university teams comprised of students (many in engineering) and faculty. One unique aspect of this program is that the partnerships and projects are long-term, so that students work with the community partners over many semesters. This allows for in-depth and thorough problem solving, as well as relationship building.

Our university team works with the Rehabilitation Medicine Department of the University of Wisconsin Hospitals (hereafter referred to as the "client".) Our students have worked on a variety of projects including: redesign and fabrication of a cart-based system used for storage of vital sign equipment routinely used by the medical staff in caring for their patients, research and possible redesign of an electronic patient escort system, and design of a clinical education program for students interested in rehabilitation engineering. Students have also engaged in study of the way communication is carried out in Rehabilitation Medicine, because there have been continuous examples where problems in communication between medical staff resulted in problems in patient care. 
To date, there have been some returning students each semester, with the rest of the team being comprised of students that are new to the projects and the client. Each semester, after the team forms and develops operating procedures, a meeting takes place with the client to discuss the up-coming semester's activities. The team prepares carefully for this meeting since they want to define what they will do for the semester as carefully and completely as possible. They have learned quickly that a semester is a short time in which to accomplish much on these projects.

During this first meeting with our client in the semester of the faculty project, a number of project ideas were discussed and considered. After the meeting the students discussed and identified the projects they wanted to work on for the semester. However, after the students had chosen the projects they wanted to pursue, one project remained that had been highlighted to us by the client as one of particular interest. What to do? We thought about it for approximately $1.7 \mu \mathrm{sec}$ and decided that we, the faculty, would carry out this project. We knew a bit of what we were getting in to, since we had previous experience to draw from.

There were some contextual differences between this project and the first. In this faculty project, there were the two of us, as opposed to the 12 faculty involved in the first project. We were advising one student team as opposed to 16 student teams. In addition, the client for our design was the same client that the students were working with. This was not the case in the first project. These contextual differences shaped the experiences and resulted in different outcomes.

Illustrated in Fig. 2, is a patient escort monitoring system used by Rehab Medicine in providing vital sign monitoring to patients with complex needs. For example, if a patient were receiving blood, or was being administered a different medicine protocol, the patient may have continuous vital sign monitoring using this system. The vital sign monitoring may occur at bedside, or may travel with the patient as the patient moves to different specialties in the hospital.

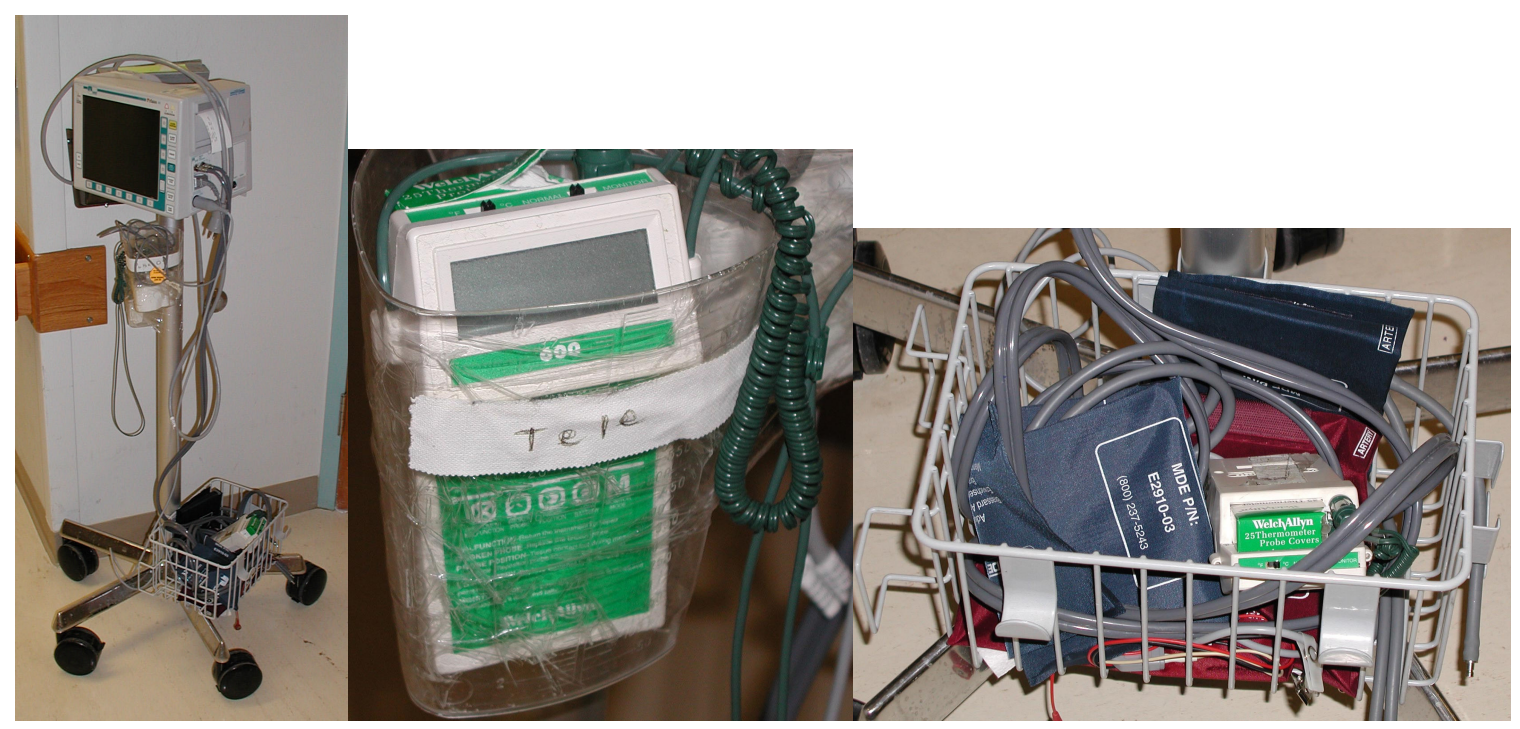

Figure 2. The Patient Escort Monitor System, showing details of one of the methods used to store equipment, and the means for cord storage, before design project was carried out. 
The problem we were presented with is apparent in Fig. 2. There are a number of transducers used for the acquisition of vital signs. Each transducer is connected to the monitor through wires or hoses. As a result, the system is a mess of parts, wires and hoses that make its use cumbersome.

Suffice to say that this was an interesting design problem that both faculty and students could relate to. We examined a multitude of design enhancements, ranging from redesign of the whole process of patient escort monitoring, to simple changes such as changing the packing tape with improved duct tape. In the end, we settled on a series of mechanical design improvements that were able to be implemented rapidly, with a plan to spend additional effort in the future on the larger issue of efficiency in patient escort monitoring. Rather than present the details of the process we followed, we will just show the final result from this endeavor, pictured in Fig. 3. This prototype is currently undergoing testing at the hospital and we will evaluate the effectiveness of the changes made in the coming months.

\section{What Happened This Time? What was the Impact?}

When the students learned that we were going to carry out one of the projects, there were a couple of reactions we had not anticipated. First, students questioned why we wanted to do a project. Because we were unprepared for this question, we did not respond with any reference to the pedagogical intent of our actions. Instead, we replied that we thought that the project needed doing and it would be good for us to do it. Students next questioned if we weren't, in fact, taking away a project that should and could be done by students in following semesters. Again, we were unprepared for this question, and because we believe that there are an unlimited number of projects worth pursuing, we thought our involvement would relieve the students of a feeling of responsibility for this project. Finally, it was clear that some of the students did not think we were serious.

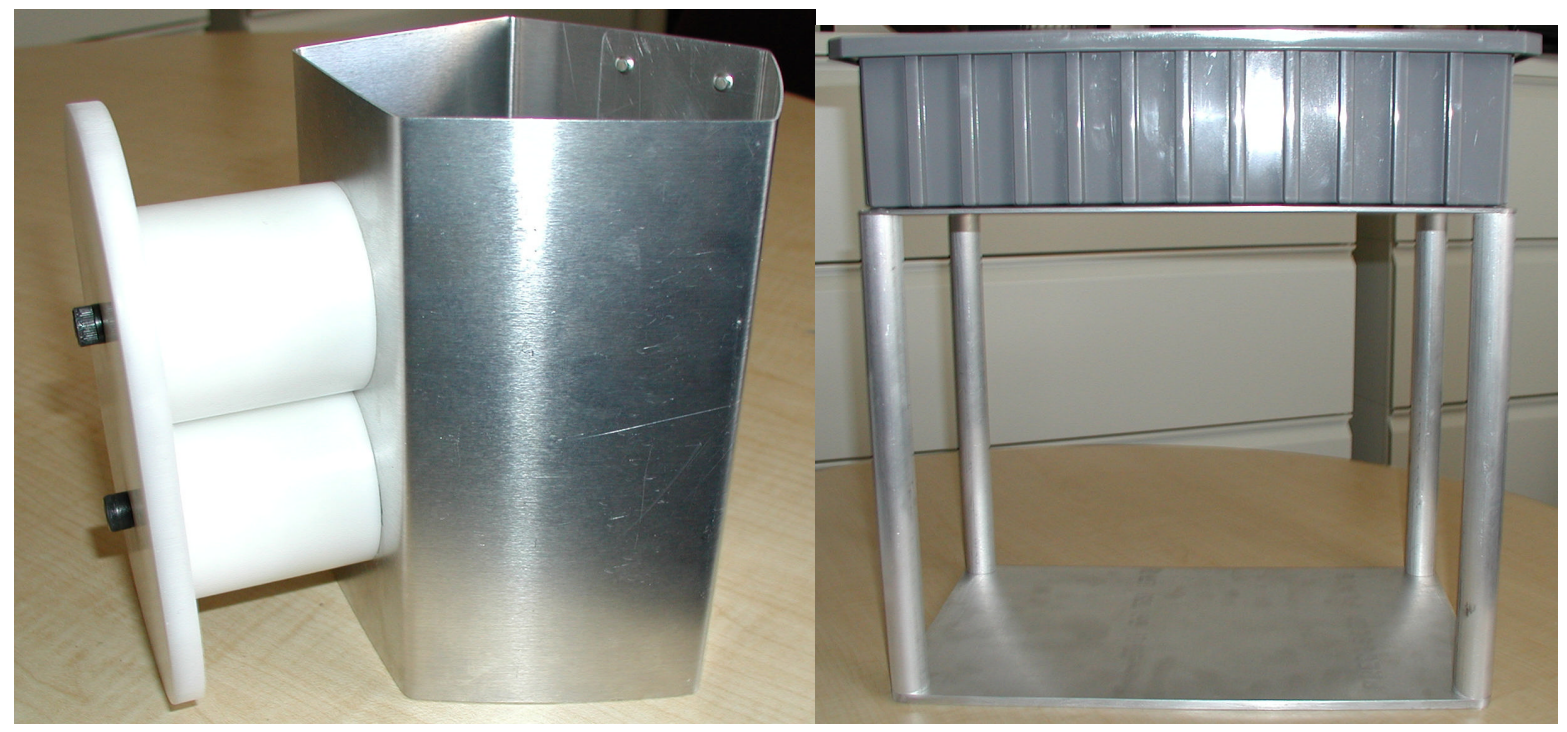

Fig. 3 Parts of the completed design project showing the cord and hose storage system developed and the system for organization and storage of the transducers. This system is currently being implemented.

In the end, we think the effort was meaningful to all parties. For example, at the end of each semester, the team typically meets with the client to describe their work and present results. 
Usually we've used this activity as an opportunity to work directly with the students in preparing and presenting a professional presentation. We do this by having a presentation "review" session several days before the meeting with the client, during which time many comments on the content and quality of the presentations are made and exchanged. Students and faculty both engage in the review of all of the presentations. However, this time, because we were presenting to the client also, we participated in the review session. As it was very near the end of the semester, we (the faculty design team) were very busy with other classes, completing the fabrication of the design, etc., and we assumed that we could throw together a presentation that would be adequate without too much thought or effort. We proved how wrong that was, and grabbed the students' attention at the review session when we fumbled through a poor presentation. The students provided a lot of constructive comments on how we could improve our presentation. Receiving direct student feedback on our work was a new experience for us. In response to the feedback we decided to make the effort necessary, redid the entire presentation, and presented the revised version at the meeting with our client. The students were surprised that we had completely revised what they had seen and made improvements. It was obvious from some of the students' comments that this had been another interaction between the faculty and students that had meaning.

\section{V) Summary}

In two different experiential design courses, the faculty carried out a design project from concept to hardware. These experiences suggest that there are different dynamics that occur between students and faculty when both parties are co-learners. In particular, providing a model for students, and engaging in a parallel experience with the students leads to new ways of interaction. In addition, it can provide a frame of reference for students to which they can compare their own work.

Despite many of the concerns faculty may have about engaging in this approach to teaching, our experience suggests that there are many different ways to make this activity workable for the faculty. What is important is identifying some of the issues and concerns prior to participation, and looking for ways to mitigate the discomfort. It is encouraging to note that some of the discomfort one may feel in learning/working alongside students fades with each new experience. In our second experience we were somewhat prepared for some of the issues we would encounter, and were able to draw on our first experience despite the different nature of its context.

Finally, we believe experiential design courses are an ideal place for this kind of activity, as much of what occurs from the pedagogy mirrors what occurs in the design process, with students as both observers and participants.

\section{VI) References}

Brookfield, S.D. Developing Critical Thinkers: Challenging Adults to Explore Alternative Ways of Thinking and Acting. San Francisco: Jossey-Bass, 1990.

Cervero, R. \& Wilson, A. Power in Practice: Adult Education and The Struggle for Knowledge and Power in Society. San Francisco: Jossey-Bass, 2001. 
Dutson, A.J., Todd, R.H., Magleby, S.P. \& Sorensen, C.D. (1997). A review of literature on teaching engineering design through project oriented capstone courses. Journal of Engineering Education, 86(10), 17-28.

Purdue University EPICS Website: http://epics.ecn.purdue.edu/

Jackson, L. \& Caffarella, R. (1994). Experiential Learning: A New Approach. New Directions for Adult and Continuing Education, 62 (3)43-54.

Wilkerson, L. \& Gijselaers, W. (1996). Bringing Problem-Based Learning to Higher Education: Theory and Practice. New Directions for Teaching and Learning, 68(1), 13-22.

\section{BIOGRAPHICAL INFORMATION}

\section{JENNIFER KUSHNER}

Jennifer Kushner is an educational researcher at the University of Wisconsin-Madison. She teaches and conducts research in the areas of educational system change, program design, curricular innovation and reform, faculty development, equity and diversity, and service learning. She received her BS and MS in adult education from the University of Wisconsin.

\section{JAY K. MARTIN}

Jay K. Martin is a Professor of Mechanical Engineering at the University of WisconsinMadison. He received an $\mathrm{AB}$ in Physics from Indiana University, an MS in Engineering Science from the University of Tennessee and a Ph.D. in Mechanical Engineering from the University of Michigan. He teaches courses in thermal sciences and design, and does research in rehabilitation engineering and assistive technology. 